\title{
Effect of manufacturing parameters on the linear expansion and density profile of particleboard
}

Original article

Shigehiko SUZUKI (Faculty of Agriculture, Shizuoka University) (Corresponding $\bowtie$ )

Kohta MIYAMOTO (Faculty of Agriculture, Shizuoka University)

Address of authors:

Faculty of Agriculture, Shizuoka University, 836-Ohya,

Shizuoka, 422-8529 Japan

Phone: +81-54-238-4854, Fax: +81-54-237-3031,

E-mail: s-suzuki@agr.shizuoka.ac.jp 


\begin{abstract}
Particleboards were fabricated in the laboratory with different board densities and resin contents to evaluate the linear expansion when exposed to both vapor and liquid water. Density profiles were measured to determine the relationship to the elastic constants and to the dimensional properties of the boards. It was found that density profiles were affected by board density and resin content applied. The high density layer formed in the thickness direction affected the elastic constant measurements. A model introduced to predict the linear expansion closely matched the data during exposure to water. In the humid condition at $40{ }^{\circ} \mathrm{C}$ and $90 \%$, linear expansion increased with increasing board density. An increase in resin content from $6 \%$ to $12 \%$ slightly increased the linear expansion, while it decreased the thickness swelling. A linear relationship was found between the board density and the linear expansion per unit moisture content change.
\end{abstract}

Key words: Particleboard, Linear expansion, Density profile, Elastic constant

\title{
Introduction
}

When wood-based panel products are exposed to humid conditions, dimensional changes take place. Linear expansion (LE) of the board is considerably smaller than thickness swelling (TS). However, the practical importance of LE has increased recently as well as TS, because these boards are used as longer elements than before.

Research determining the LE of reconstituted wood-based boards are not as common compared with research for TS in which the effects of board making parameters were discussed to improve dimensional stability in the thickness direction. Furthermore, LE has been measured as additional data in the research works where mechanical properties or other items were discussed $1-9$.

Only a few papers have dealt with LE as a main topic. Vital et al. ${ }^{10}$ reported on LEs and TSs of flakeboard and particleboard exposed to different humid conditions. Suchsland ${ }^{11}$, Suchsland and Xu- $\mathrm{H}^{12}$, and $\mathrm{Xu}-\mathrm{W}$ and Suchsland ${ }^{13}$ focused on the measuring of LE and the modeling of the mechanism of LE in particleboard. However, there was less information on how the board fabricating parameters affected the LE of wood-based panel products.

The objective of this paper was to evaluate the effects of board density and resin content (RC) on the LE of the particleboard exposed to both vapor and liquid water followed by a drying test. Density profiles and elastic constants of the boards, affected by the fabricating parameters, were determined to explain the relation to LE.

\section{Materials and Methods}

Particleboard Manufacturing

Homogenous boards, 340 by 320 by $10 \mathrm{~mm}$, were constructed using knife-ringflaker particles with average dimensions of $18.6 \mathrm{~mm}$ in length, $3.7 \mathrm{~mm}$ in width and $0.48 \mathrm{~mm}$ in thickness. These particles were obtained from 
sugi (Japanese cedar, Cryptomeria japonica D. Don), and had an oven-dry density of $0.39 \mathrm{~g} / \mathrm{cm}^{3}$. The furnish was dried to a moisture content of less than $3 \%$ before gluing. Duplicate boards were made at each of the following five density levels, $0.4,0.5,0.6,0.7$ and $0.8 \mathrm{~g} / \mathrm{cm}^{3}$ and at each of the following four resin content levels, 3, 6, 9, and $12 \%$ of solid weight basis. The mat moisture content before pressing depended on RC; it was $6.4 \%, 9.9 \%$, $13.3 \%$, and $16.3 \%$ for RC of $3 \%, 6 \%, 9 \%$, and $12 \%$, respectively. Boards with a density of $0.7 \mathrm{~g} / \mathrm{cm}^{3}$ and $9 \%$ $\mathrm{RC}$ were made to serve as controls. Board construction factors were as follows:

Resin: Commercial liquid phenolic resin, $41 \%$ solid,

Wax: Not applied,

Press temperature: $180^{\circ} \mathrm{C}$,

Pressure: 3.5 MPa,

Total press time: 7.5 minutes,

Surface: Not sanded.

The closing time depended on the board density designed. It was approximately 15 seconds and 50 seconds for a $0.4 \mathrm{~g} / \mathrm{cm}^{3}$ board and a $0.8 \mathrm{~g} / \mathrm{cm}^{3}$ board, respectively.

Mechanical Properties

The manufactured boards were trimmed to 300 by $300 \mathrm{~mm}$ square and tested for flexural stiffness $(E b)$ and plate shear modulus $(G)$ without being failed. Additional tests for these elastic constants were made with a vibration method using a FFT analyzer for checking the constants obtained with static tests. Ebs and Gs were determined from the peak frequency of power spectrum of the tone by tapping the edge of the specimen ${ }^{14}$.

Boards were cut down to 300 by $50 \mathrm{~mm}$ for the dimensional stability tests. Three kinds of Young's moduli (E1, E2, and E3) of each specimen were also determined by the vibration method. E1, E2, and E3 were elastic constants obtained using the flat-wise bending vibration, the edge-wise bending vibration, and the longitudinal vibration methods, respectively. These constants were calculated as follows:

$$
\begin{gathered}
E 1 \text { and } E 2=48 \pi^{2} \mathrm{~L}^{4} \rho \mathrm{f}^{2} /\left(\mathrm{h}^{2} \mathrm{~m}^{4}\right), \\
\text { E3 } \quad=4 \mathrm{~L}^{2} \rho \mathrm{f}^{2},
\end{gathered}
$$

where $\mathrm{L}$ is the length, $\rho$ is the density of the specimen, and $\mathrm{h}$ is the height of the beam vibrating. The $\mathrm{h}$ was the thickness of the specimen for $E 1$ measurement, while it was the width for E2. $\mathrm{f}$ is the peak frequency and $\mathrm{m}$ is the constant (4.730 for first vibration mode). 15

\section{Density Profile}

Density gradient in the thickness direction of the specimens were measured using a commercial density-profiler based on a gamma radiation system. Specimens with dimensions of 50 by $50 \mathrm{~mm}$ were used, and the measurement was made at $0.1 \mathrm{~mm}$ intervals.

\section{Dimensional Change}


Prior to testing, all specimens, each $50 \mathrm{~mm}$ wide by $300 \mathrm{~mm}$ long, were conditioned in an air-circulating chamber at $60{ }^{\circ} \mathrm{C}$ for 24 hours to get constant moisture conditions and initial dimensions. Three samples were selected randomly for each test: 1) exposed to vapor at $40{ }^{\circ} \mathrm{C}$ and $90 \% \mathrm{RH}$ (humidity test), and 2) immersion in liquid water at room temperature (immersion test). After reaching saturation in each test, samples were dried to equilibrium in the chamber at $40{ }^{\circ} \mathrm{C}$. No sealing was done so that moisture could move through the faces and edges. The length, thickness and weight of the specimens were measured at certain intervals during both the humidity and the immersion tests.

Linear expansion (LE), thickness change (TS), and weight change (WA: water absorption) were calculated on the basis of the initial dimensions. LE was determined by measuring the length of the specimen to the nearest $0.01 \mathrm{~mm}$ accuracy using equipment according to $\mathrm{ASTM}^{16}$.

\section{Results and Discussion}

Mechanical Properties

Bending stiffness $E b$ and plate shear modulus $G$ obtained by the non-destructive static tests are listed in Table 1 . These elastic constants increased with increasing board density and resin content. The same results were reported by Kelly ${ }^{17}$. Elastic constants of 300 by $50 \mathrm{~mm}$ specimens obtained by the vibration methods are shown in Fig. 1, where all of the constants increased with increasing density.

E2 and E3 showed a similar increasing trend against the board density. These two constants were thought to be representing an average elastic constant throughout the thickness of the board, because E3 was based on the longitudinal vibration of the specimen and $E 2$ was based on the edge-wise in-plane bending vibration. In this edge-wise vibration, the ratio of length to height of the beam, 300/50, was not enough to eliminate a shear effect of the beam. This can be a reason that $E 2$ was lower than $E 3$ for all the board density tested in this experiment. E1 value, obtained by the out-of-plane bending vibration, was close to $E 3$ at density $0.4 \mathrm{~g} / \mathrm{cm}^{3}$, however, it became almost the same value as $E 2$ when the board density was $0.8 \mathrm{~g} / \mathrm{cm}^{3}$. It was shown that higher density of the board gave a relatively lower $E 1$ in the elastic constant measurements. This could be due to the effect of layer construction of the board.

Figure 2 shows the relationship between RC and the elastic constants. In the RC range from $6 \%$ to $9 \%$, E1 obtained by the flat-wise bending vibration increased remarkably, although E2 and E3 showed only slight increases. The same consideration mentioned above that E1,E2 and E3 depends on the layer structure can be done on the behavior shown in Fig. 2. However, the elastic constants at $3 \% \mathrm{RC}$ were excluded from this analysis, because the appearance of the board with $3 \% \mathrm{RC}$ was somewhat different from the others, i.e., its spring back after the pressing was larger than the other boards as shown in the thickness data in Table 1.

\section{Density Profile}

The density gradients in Fig. 3 shows the many density measurements obtained for samples with different average board densities. The results showed a typical density gradient for particleboard 18 having high density layers just inside the board surfaces. 
It was found in Fig. 3 that the high density layer moved toward the inner layers with increasing board density. Polynomial regressions of the density data confirmed this result. It revealed that the peak density was located around $0.6 \mathrm{~mm}$ inside the surface for a $0.4 \mathrm{~g} / \mathrm{cm}^{3}$ board and $1.1 \mathrm{~mm}$ for a $0.8 \mathrm{~g} / \mathrm{cm}^{3}$ board.

The location of the high density layer affected the elastic constant $E 1$, because the $E 1$ measurement was based on an out-of-plane bending vibration. It was obvious that a high density layer located on the outer layers in the board will give higher bending stiffness rather than that located on the inner layers. Thus the behavior of E1 shown in Fig. 1 can be explained qualitatively by the fact that the high density layer shifted into the inner layers as the board density increased.

Figure 4 also shows the density gradients of the same average density boards fabricated with various resin contents. No high density layer was found in the $3 \% \mathrm{RC}$ board. Low RC and low mat moisture content were thought to be the reasons that a high density layer was not formed in this kind of board during hot pressing.

In the RC range from $6 \%$ to $12 \%$ the position of the peak density seemed to shift outwards and the peak density itself became larger when RC of the board increased. This fact of layer construction of the board, which was also confirmed by the 8th-order polynomial regression, was reflected by the elastic constant measurements as shown in Fig. 2. This was the main reason that E1 behavior was different from E2 and E3.

\section{Dimensional Changes}

Using the specimens having such density profiles and elastic characteristics mentioned above, linear changes and thickness changes were determined for evaluating the effects of the board fabricating factors of density and RC.

\section{Effect of board density on LE}

The linear expansion behavior of the boards with various densities during the humidity test at $40{ }^{\circ} \mathrm{C}$ and $90 \% \mathrm{RH}$ is shown in Fig. 5. Measurements were continued until the reaching equilibrium at which weight change occurred at less than $0.1 \%$ per 24 hours. Fig. 5 shows the LE changes of the first 50 hours within the total measurements made up to 210 hours.

Linear expansions for all the boards increased rapidly at the beginning of the humidity test, and leveled off toward saturation values. LE of the lowest density board, $0.4 \mathrm{~g} / \mathrm{cm}^{3}$, seemed to reach its saturation value at around 10 hours, whereas LE of $0.8 \mathrm{~g} / \mathrm{cm}^{3}$ board was still increasing after 50 hours. Fig. 5 also shows that the larger the board density, the higher the saturation LE value and the more time required to reach it.

For evaluating the LE change vs. exposure time, the exponential equation, which had been used for describing thickness changes of particleboards or $\operatorname{MDF}^{19,20}$, was employed:

$$
T=\alpha(1-\exp (-t / \beta)) \quad(1),
$$

where $T$ is linear expansion, $t$ is time, and $\alpha$ and $\beta$ are empirical constants. The constant $\alpha$ represents an estimated saturation value when $t$ tends to infinity, and the constant $\beta$ indicates a rate of increase.

The curves, which were obtained by the non-linear least squares regression, were in good agreement with the experimental data as shown in Fig. 5. Thus it was concluded that this equation can be used for LE prediction as well as TS. 
Since the constant $\beta$ indicated the time until which LE reaches about $63 \%$ of the saturation value, $\alpha(1-e)$, the increasing rate of each LE curve can be compared using $\beta$. Rate of increase, $\beta$, increased with increasing density as shown in Table $2 ; \beta$ of the $0.4 \mathrm{~g} / \mathrm{cm}^{3}$ board was about $1.7 \mathrm{~h}$ while that of the $0.8 \mathrm{~g} / \mathrm{cm}^{3}$ board was 16.2 h. As shown in Table 2 the $\beta$ increased by a factor of approximately 1.8 times for each $0.1 \mathrm{~g} / \mathrm{cm}^{3}$ increase of the board density.

\section{LE per unit MC change}

Dimensional test results of both the humidity test and the immersion test are summarized in Table 3. LE and WA after reaching equilibrium at $40{ }^{\circ} \mathrm{C}$ and $90 \% \mathrm{RH}$ are listed in this table. It was obvious that LE increased with increasing density according to moisture change. The WA's in the humidity test ranged from $15.3 \%$ to $16.8 \%$ and were based on the initial weights before testing. For better understanding, LE behavior was recalculated on the basis of MC change, LE/MC, instead of evaluating LE/WA.

Figure 6 shows the relationship between LE/MC and board density. There was a strong linear relation between the board density and LE/MC, and the following regression equation was obtained.

$$
L m=0.016+0.012 \rho \quad(2)
$$

where $\mathrm{Lm}$ is LE per unit MC change. LE/MC changed from 0.021 to $0.026 \% / \%$ corresponding to the density range from $0.4 \mathrm{~g} / \mathrm{cm}^{3}$ to $0.8 \mathrm{~g} / \mathrm{cm}^{3}$. This equation can provide predictions on linear change of particleboard in service conditions, because the MC change of this humidity test ranged from about $2 \%$ to $18 \%$. However, it should be noted that the LE/MC could be affected by parameters other than density, such as resin type, particle shape, and so on.

\section{EL and TS in the humidity test}

One of the factors to be noted was the increasing rates of LE and TS during the humidity test. Thickness swelling (TS) during the humidity test was also evaluated using the same equation, Eq.(1). The experimental data, not shown here, was in agreement with the curves drawn by the Eq.(1). The value $\beta$ listed in Table 2 showed that TS of the high density board needed more time to reach the saturation.

The behaviors of LE and TS in the humidity test were different in time dependence. TS was continuing to increase after LE had almost reached its saturation. This trend was confirmed by comparing the $\beta \mathrm{s} ;$ the $\beta$ for TS was much larger than that of LE.

This difference could be due to the fact that the LE measured here appeared as an average value of expansion in each layer of the board. Some restrictions in the plane directional expansion might occur between the layers when each layer has different potential to expand according to the moisture change. TS was qualitatively thought to be a sum of expansion in thickness direction of each layer.

\section{Effect of vapor and liquid water}

Table 3 lists the data for LE, TS, and WA determined at absorption (wet) conditions and under desorption (dry) conditions that followed the humidity or immersion test. 
Dimensional changes (LE and TS) of the immersion test were slightly larger than those of the humidity test for all the board densities tested in this experiment. However there were remarkable differences in WAs for the humidity test and immersion test.

One of the differences to be noted was found in LE's of dry conditions. LE's of dry conditions after the water immersion ranged from -0.28 to $-0.13 \%$, while those after the humidity test were close to zero. This showed that the specimen reduced its length after water immersion followed by drying at $40{ }^{\circ} \mathrm{C}$. This shrinkage was possibly caused by the "Poisson's effect" corresponding to the thickness changes.

\section{Effect of resin content in the humidity test}

Figure 7 shows the relationship between exposure time and LE of the board with different RC conditions. The data of the first 100 hours were shown, even though the measurement had been continued up to 270 hours. Shape of the curves was almost the same as the LE changes in Fig. 5, and the Eq.(1) can be applied to predict the behavior.

The board with $3 \%$ RC exhibited the different behavior from the others because of the layer structure shown in Fig. 4. In the RC range from $6 \%$ to $12 \%$, the difference among the boards was small but clear. At the beginning of the exposure, $6 \% \mathrm{RC}$ board showed the largest LE among three and the LE curves crossed over at around 27 hours. Finally the high RC board had more LE than low RC board when the sample reached the leveling off stage.

No clear reason of this phenomenon was drawn here, however, differences of the layer structure and hygroscopicity of PF resins cured in the board could be candidates to be investigated. Further research will be necessary in this area.

Figure 8 shows the relationship between RC and LE per unit MC change. High value for $3 \%$ RC board was due to the low bond quality and the different layer structure. No significant difference was observed in $\mathrm{LE} / \mathrm{MC}$ between $6 \% \mathrm{RC}$ and $12 \% \mathrm{RC}$ board. This proved that the high LE of high RC board was caused only by the larger amount of water the specimen can absorb compared with the low RC board.

\section{Conclusion}

This study evaluated the effects of board density and RC on the LE and density profile of particleboard. Results obtained were summarized as follows. The high density layers in the thickness direction of the board shifted inwards, as the average board density increased. The density profile was also affected by the RC applied. The elastic constants determined by the three vibration test methods qualitatively depended on the density profiles formed under various board density and RC conditions. It was found that Equation (1) was effective in predicting the $\mathrm{LE}$ behavior of the board exposed to both vapor and liquid water. In the humidity test at $40{ }^{\circ} \mathrm{C}$ and $90 \% \mathrm{RH}$, LE increased with increasing board density. An increase in RC from $6 \%$ to $12 \%$ slightly increased LE. The linear relationship between LE/MC and board density presented by Eq. (2) was found, whereas LE/MC remained constant for the RC change form $6 \%$ to $12 \%$. 
Acknowledgment Authors would like to thank Professor Dr. Sobue, Shizuoka University, for his suggestion in conducting this research.

\section{References}

1. Vital BR, Lehmann WF, Boone RS (1974) How species and board densities affect properties of exotic hardwood particleboards. Forest Prod J 24(12):37--45

2. Hse CY (1975) Properties of flakeboards from hardwoods growing on Southern pine sites. Forest Prod J 25(3):48--53

3. Shuler CE, Kelly RA (1976) Effect of flake geometry on mechanical properties of Eastern Spruce flake-type particleboard. Forest Prod J 26(6):24--31

4. Chow P (1979) Phenol adhesive bonded medium-density fibreboard from Quercus rubra L. bark and sawdust. Wood and Fiber, 11(2):92--98

5. Sekino N, Suzuki, M (1984) Swelling and creep of isocyanate-bonded oriented-particleboard (in Japanese). Mokuzai Gakkaishi, 30(1):17--22

6. Kajita H (1987) Oriented particleboard with sugi thinnings (Cryptomeria japonica) I, Effects of degree of particle alignment and board density on physical and mechanical properties. Mokuzai Gakkaishi, 33(11):865$-871$

7. Avramidis S, Smith LA (1989) The effect of resin content and face-to-core ratio on some properties of oriented strand board. Holzforschung 43(2):131--133

8. Au KC, Gertjejansen RO (1989) Influence of wafer thickness and resin spread on the properties of paper birch waferboard. Forest Prod J 39(4):47--50

9. Sun BCH, Hawke RN, Gale MR (1994) Effect of polyisocyanate level on physical properties of wood fiber composite materials. Forest Prod J 44(4):53--58

10. Vital BR, Wilson JB, Kanarek PH (1980) Parameters affecting dimensional stability of flakeboard and particleboard, Forest Prod J 30(12):23--29

11. Suchsland O (1972) Linear hygroscopic expansion of selected commercial particleboards. Forest Prod J 22(11):28--32

12. Suchsland O, Xu H (1989) On the measurement of linear expansion of particleboard and medium density fiberboard. Forest Prod J 39(6):39--42

13. Xu W, Suchsland O (1997) Linear expansion of wood composites, A model. Wood and Fiber Sci 29(3):272-281

14. Sobue N, Kato A (1992) Simultaneous determination of orthotropic elastic constants of strand full-size plywoods by vibration method. Mokuzai Gakkaishi 38:895--902

15. Dong Y, Nakao T, Chiaki T, Tanaka A, Nishino Y (1992) Evaluation of the characteristics of wood based panels by the in-and out of-plane vibration technique (in Japanese). Mokuzai Gakkaishi 38:678--686

16. ASTM D 1037-92 (1992) Standard methods of evaluating the properties of wood-based fiber and particle panel materials, Linear variation with change in moisture content.

17. Kelly MW (1977) Critical literature review of relationships between processing parameters and physical properties of particleboard. USDA General technical report FPL-10, pp36--44 
18. Laufenberg TL (1986) Using gamma radiation to measure density gradients in reconstituted wood products. Forest Prod J 36(2):59--62

19. Suzuki S, Saito F, Arima T (1985) Properties of particleboards made form wood element from demolished building (in Japanese). Wood Industry 40(1):15--20

20. Suzuki S, Saito F (1988) Fatigue properties of particleboards I, Effect of aging treatment on tensile properties parallel to the surface. Mokuzai Gakkaishi 34:590--596

Table 1. Elastic properties obtained by static tests and thickness after hot pressing.

\begin{tabular}{ccccc}
\hline $\begin{array}{c}\text { Target board } \\
\text { density }\left(\mathrm{g} / \mathrm{cm}^{3}\right)\end{array}$ & $\begin{array}{c}\mathrm{RC} \\
(\%)\end{array}$ & $\begin{array}{c}\text { Thickness } \\
(\mathrm{mm})\end{array}$ & $\begin{array}{c}E b^{\mathrm{a}} \\
(\mathrm{GPa})\end{array}$ & $\begin{array}{c}G^{\mathrm{b}} \\
(\mathrm{GPa})\end{array}$ \\
\hline 0.4 & 9 & 9.99 & 1.12 & 0.58 \\
0.5 & 9 & 9.96 & 1.71 & 0.87 \\
0.6 & 9 & 9.91 & 2.18 & 1.13 \\
& 3 & 10.5 & 1.63 & 0.84 \\
0.7 & 6 & 9.99 & 2.56 & 1.19 \\
& 9 & 9.78 & 2.70 & 1.42 \\
0.8 & 12 & 9.62 & 3.59 & 1.56 \\
& 9 & 9.75 & 3.49 & 1.55 \\
\hline
\end{tabular}

$\mathrm{RC}$, resin content; Eb, flexural stiffness; $\mathrm{G}$, plate shear modulus.

${ }^{a}$ Modulus of elasticity obtained by the static bending test.

${ }^{\mathrm{b}}$ Modulus of rigidity obtained by the static plate shear test.

Table 2. Coefficient $\beta$ for LE and TS changes in the humidity test.

\begin{tabular}{ccc}
\hline $\begin{array}{c}\text { Board density } \\
\left(\mathrm{g} / \mathrm{cm}^{3}\right)\end{array}$ & $\beta$ & $(\mathrm{h})$ \\
\cline { 2 - 3 } & $\mathrm{LE}$ & $\mathrm{TS}$ \\
\hline 0.4 & 1.69 & 8.10 \\
0.5 & 2.89 & 12.7 \\
0.6 & 5.63 & 16.4 \\
0.7 & 8.74 & 23.9 \\
0.8 & 16.2 & 40.1 \\
\hline
\end{tabular}

LE, linear expansion; TS, thisckness swelling; $\beta$, rate of increase

Table 3. Dimensional stability test results

\begin{tabular}{|c|c|c|c|c|c|c|c|c|c|c|c|c|}
\hline \multirow{3}{*}{$\begin{array}{l}\text { Density } \\
\left(\mathrm{g} / \mathrm{cm}^{3}\right)\end{array}$} & \multicolumn{6}{|c|}{ Humidity test } & \multicolumn{6}{|c|}{ Immersion test } \\
\hline & \multicolumn{2}{|c|}{ LE $(\%)$} & \multicolumn{2}{|c|}{ TS (\%) } & \multicolumn{2}{|c|}{ WA (\%) } & \multicolumn{2}{|c|}{ LE $(\%)$} & \multicolumn{2}{|c|}{ TS (\%) } & \multicolumn{2}{|c|}{ WA (\%) } \\
\hline & $\mathrm{W}$ & $\mathrm{D}$ & $\mathrm{W}$ & $\mathrm{D}$ & $\mathrm{W}$ & $\mathrm{D}$ & $\mathrm{W}$ & $\mathrm{D}$ & $\mathrm{W}$ & $\mathrm{D}$ & $\mathrm{W}$ & $\mathrm{D}$ \\
\hline$\overline{0.4}$ & 0.36 & 0.00 & 11.6 & 5.6 & 16.5 & 2.9 & 0.46 & -0.13 & 13.6 & 4.1 & 190 & -0.9 \\
\hline 0.5 & 0.39 & 0.00 & 14.2 & 7.2 & 16.8 & 3.1 & 0.48 & -0.16 & 16.7 & 5.8 & 150 & -0.9 \\
\hline 0.6 & 0.41 & 0.00 & 16.8 & 9.0 & 16.6 & 3.1 & 0.51 & -0.18 & 18.6 & 7.6 & 118 & -1.0 \\
\hline 0.7 & 0.41 & -0.01 & 17.0 & 8.9 & 15.5 & 3.1 & 0.50 & -0.20 & 21.5 & 9.2 & 94 & -0.6 \\
\hline 0.8 & 0.43 & -0.02 & 17.8 & 8.8 & 15.3 & 3.1 & 0.45 & -0.28 & 22.4 & 9.5 & 70 & -0.8 \\
\hline
\end{tabular}

Humidity test: exposed to the humid condition at $40{ }^{\circ} \mathrm{C}, 90 \% \mathrm{HR}$, relative humidity. Immersion test: water immersion at room temperature.

$\mathrm{W}$, wet condition and $\mathrm{D}$, dried condition at $40{ }^{\circ} \mathrm{C}$; WA, water absorption 


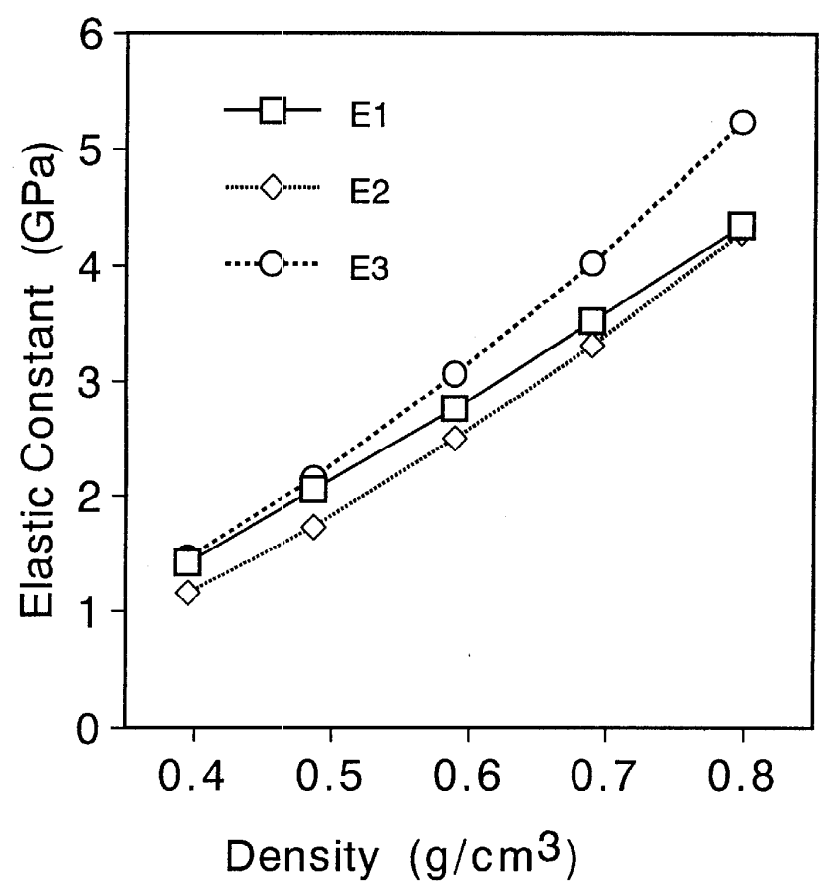

Fig. 1. Effect of board density on the elastic constant determined by vibration methods. El, flat-wise out-ofplane bending vibration; E2,edge-wise in-plane bending vibration; $E 3$, longitudinal vibration

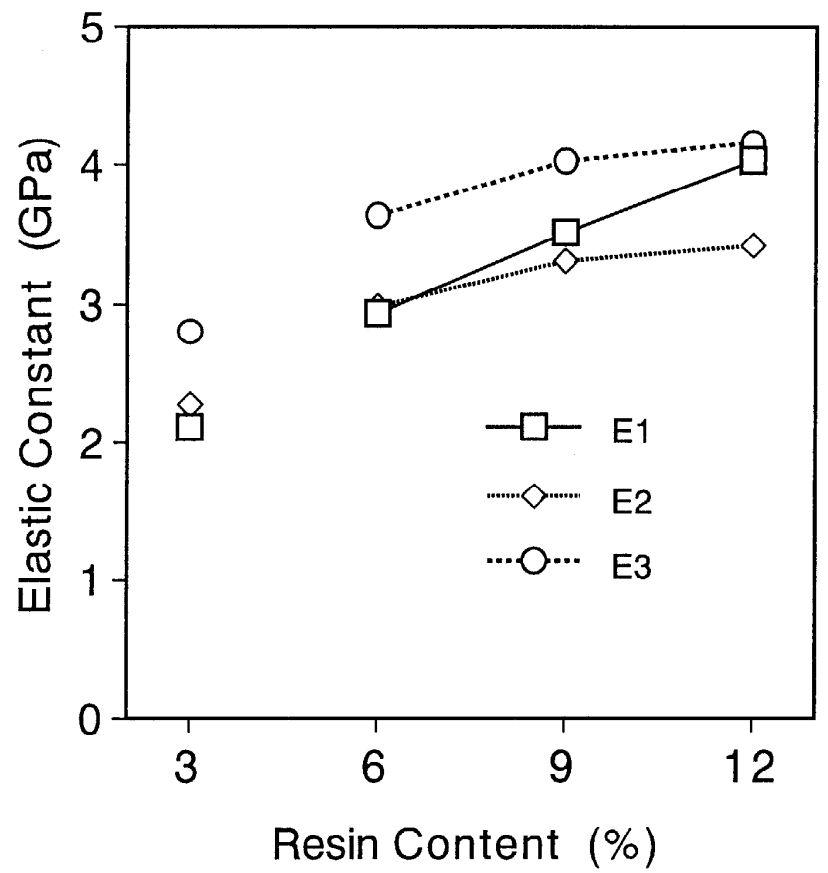

Fig. 2. Effect of resin content on the elastic constant determined by vibration methods 


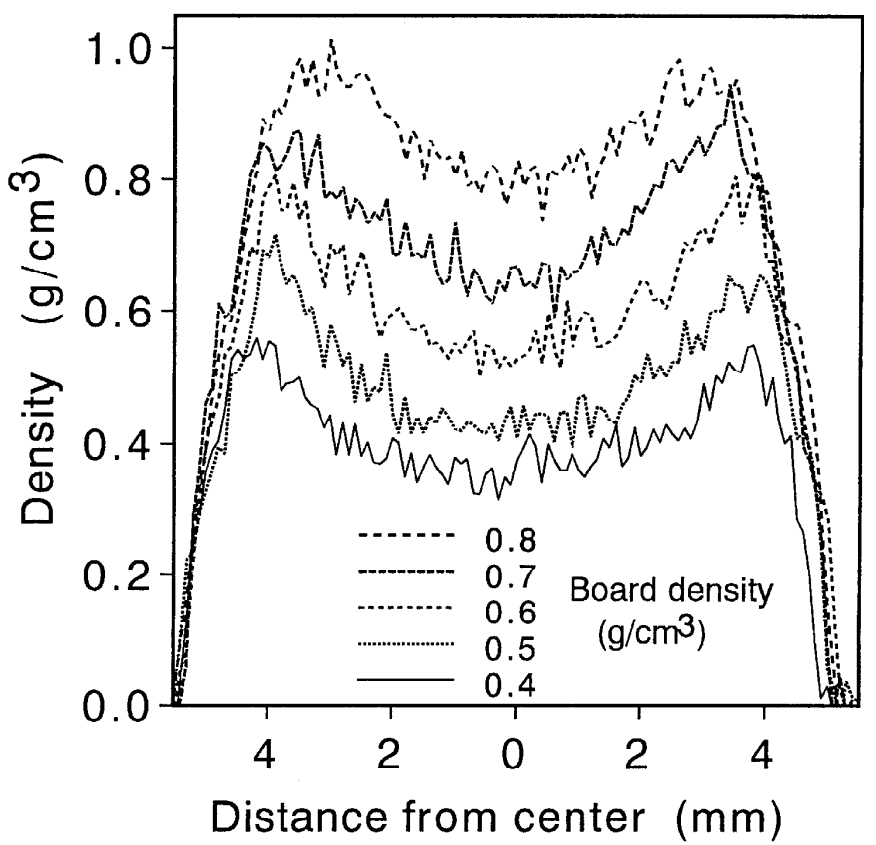

Fig. 3. Effect of board density on the density profile of particleboard

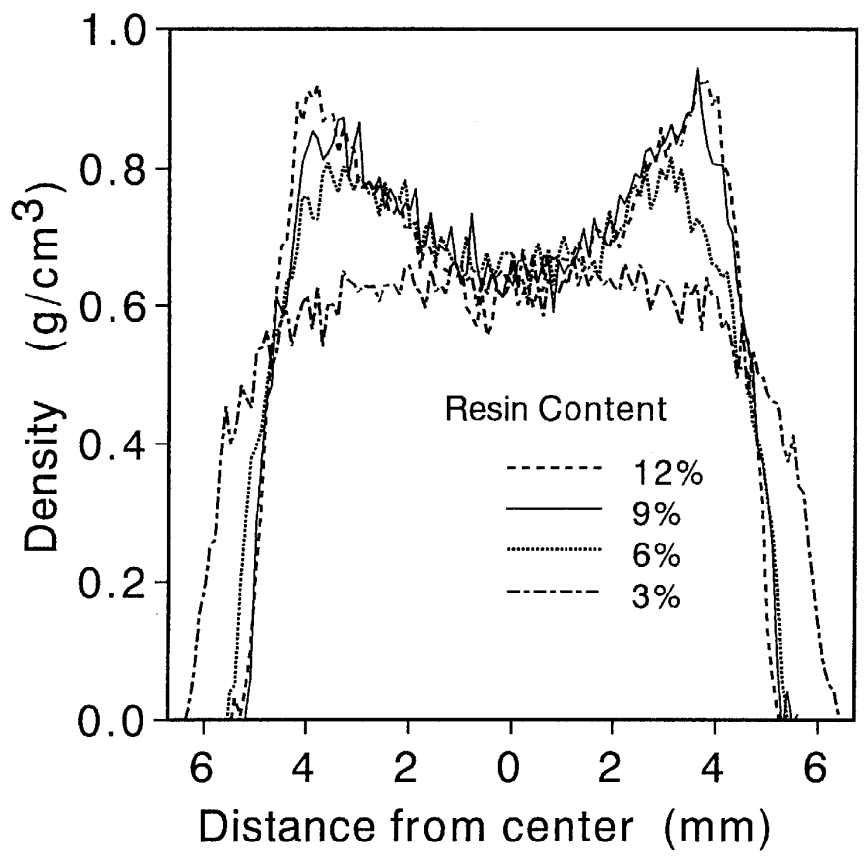

Fig. 4. Effect of resin content on the densi $\mathrm{W}$ profile of particleboard 


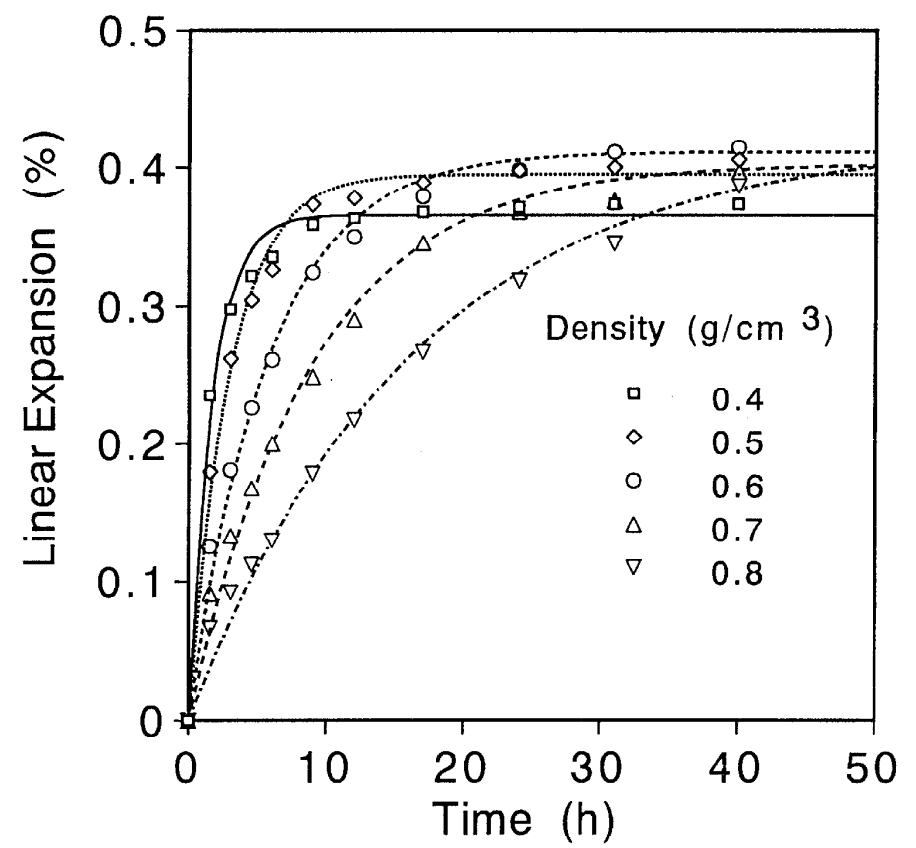

Fig. 5. Linear expansion behavior of particleboard at different densities under humid conditions at $40^{\circ} \mathrm{C}$ and $90 \%$ relative humidity $(\mathrm{RH})$

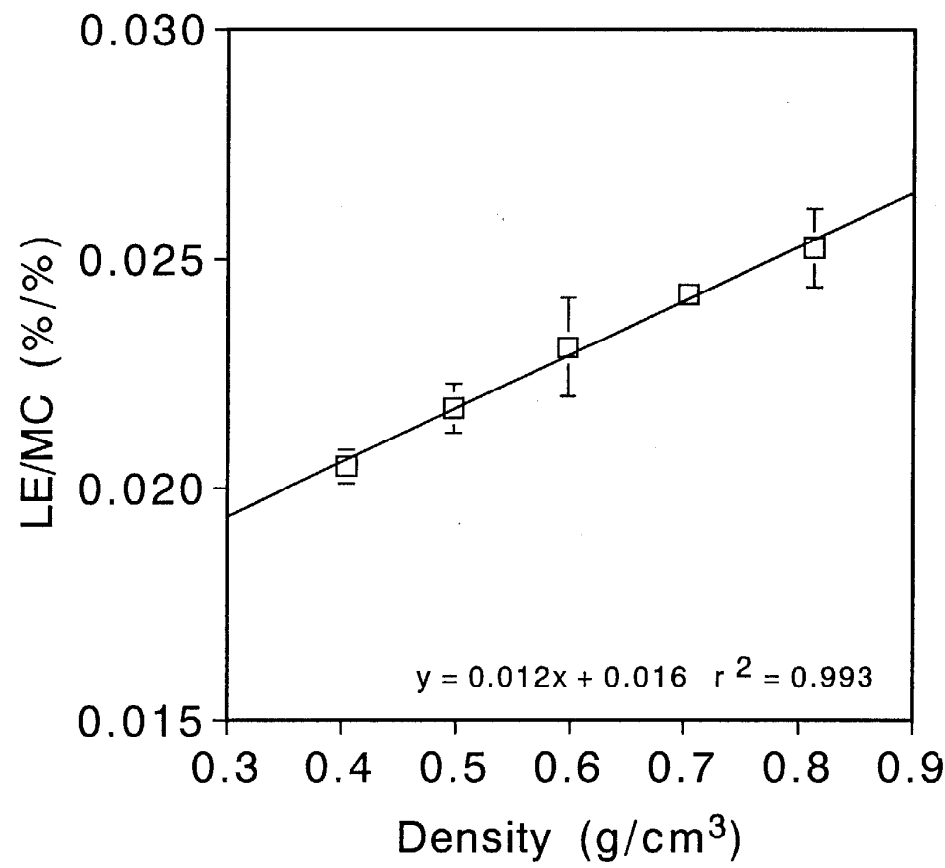

Fig. 6. Linear expansion per unit moisture content change for particleboard at various board densities during the humidity test at $40^{\circ} \mathrm{C}$ and $90 \%$ RH. Bars show one standard deviation 


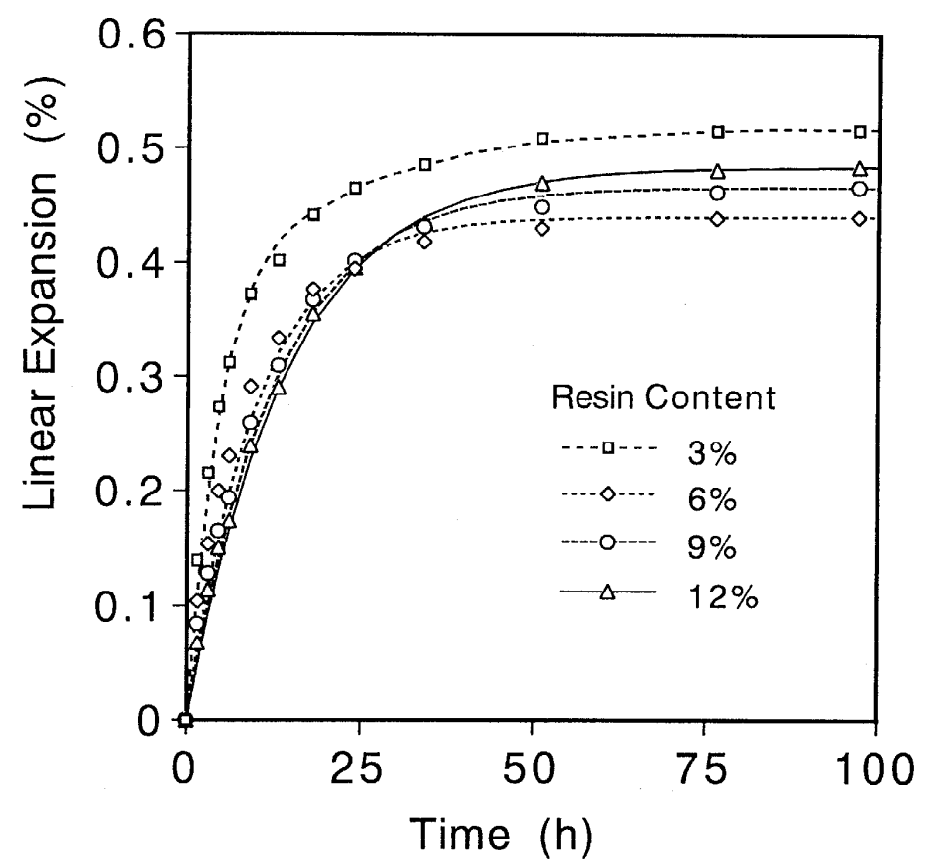

Fig. 7. Linear expansion behavior of particleboards with different resin contents under humid conditions at $40^{\circ} \mathrm{C}$ and $90 \% \mathrm{RH}$

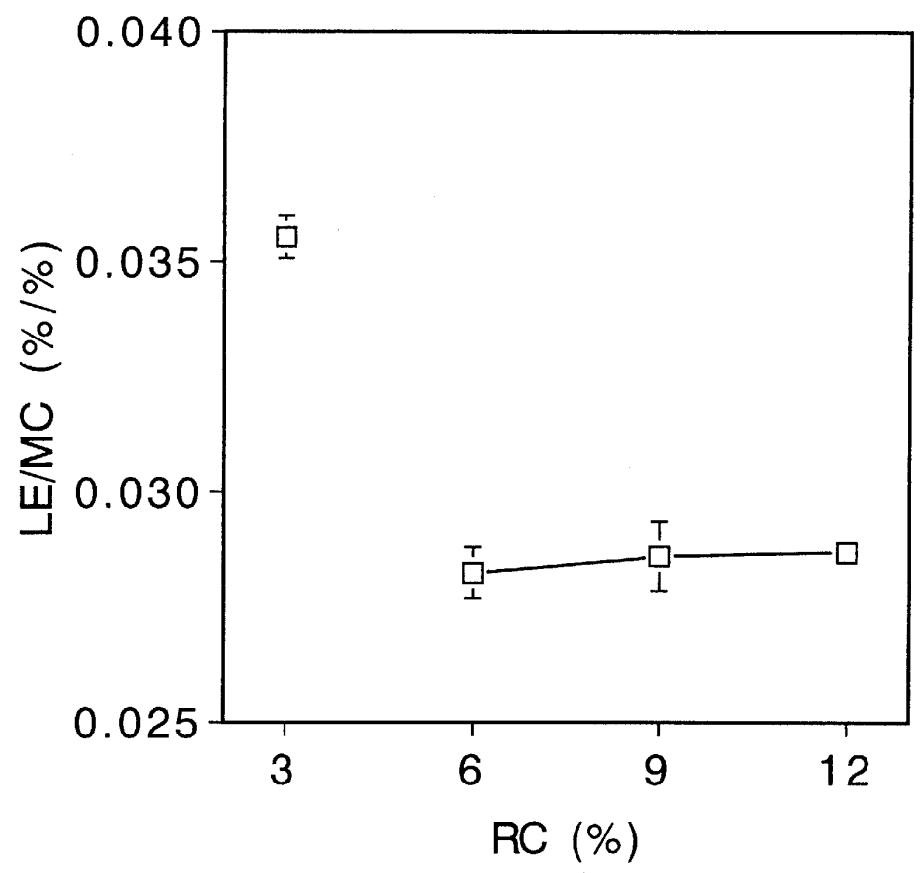

Fig. 8. Linear expansion per unit moisture content change for particleboard with various resin contents during the humidity test at $40^{\circ} \mathrm{C}$ and $90 \%$ RH. Bars show one standard deviation 